\title{
BMJ Open Assessing effective mask use by the public in two countries: an observational study
}

Clare L Atzema (D) , ${ }^{1,2,3}$ Ivona Mostarac (1) , , Dana Button, ${ }^{4}$ Peter C Austin, ${ }^{1,2,3}$ Arshia P Javidan (D) , ${ }^{3,5}$ Lauren Wintraub, ${ }^{6}$ Allen Li (D) , ${ }^{7}$ Raumil V Patel,,${ }^{3,6}$ Daniel Dongjoo Lee, ${ }^{3,6}$ Nathaniel P Latham, ${ }^{1}$ Eric A Latham, ${ }^{1}$ Patrick C M Brown, ${ }^{4}$ Rita D Somogyi, ${ }^{4}$ Alex Chang, ${ }^{4}$ Huong Nguyen, ${ }^{4}$ Sara Buerk, ${ }^{4}$ Bin Chen, ${ }^{4}$ Tristen Zimmerman, ${ }^{4}$ Trevor Funari (1) ${ }^{4}$ Cameron Colbert, ${ }^{4}$ Bory Kea ${ }^{4,8}$
To cite: Atzema CL, Mostarac I, Button D, et al. Assessing effective mask use by the public in two countries: an observational study. BMJ Open 2021;11:e049389. doi:10.1136/ bmjopen-2021-049389

- Prepublication history and additional supplemental material for this paper are available online. To view these files, please visit the journal online (http://dx.doi.org/10.1136/ bmjopen-2021-049389).

Received 28 January 2021 Accepted 29 0ctober 2021
Check for updates

(c) Author(s) (or their employer(s)) 2021. Re-use permitted under CC BY-NC. No commercial re-use. See rights and permissions. Published by BMJ.

For numbered affiliations see end of article.

Correspondence to

Dr Clare L Atzema;

clare.atzema@ices.on.ca

\section{ABSTRACT}

Objectives During the COVID-19 pandemic wearing a mask in public has been recommended in some settings and mandated in others. How often this advice is followed, how well, and whether it inadvertently leads to more disease transmission opportunities due to a combination of improper use and physical distancing lapses is unknown.

Design Cross-sectional observational study performed in June-August 2020.

Setting Eleven outdoor and indoor public settings (some with mandated mask use, some without) each in Toronto, Ontario, and in Portland, Oregon.

Participants All passers-by in the study settings.

Outcome measures Mask use, incorrect mask use, and number of breaches (ie, coming within $2 \mathrm{~m}$ of someone else where both parties were not properly masked). Results We observed 36808 persons, the majority of whom were estimated to be aged $31-65$ years $(49 \%)$. Two-thirds $(66.7 \%)$ were wearing a mask and $13.6 \%$ of mask-wearers wore them incorrectly. Mandatory maskuse settings were overwhelmingly associated with mask use (adjusted OR 79.2; 95\% Cl 47.4 to 135.1). Younger age, male sex, Torontonians, and public transit or airport settings (vs in a store) were associated with lower adjusted odds of wearing a mask. Mandatory mask-use settings were associated with lower adjusted odds of mask error (OR 0.30; $95 \% \mathrm{Cl} 0.14$ to 0.73 ), along with female sex and Portland subjects. Subjects aged $81+$ years (vs 31-65 years) and those on public transit and at the airport (vs stores) had higher odds of mask errors. Mask-wearers had a large reduction in adjusted mean number of breaches (rate ratio (RR) $0.19 ; 95 \% \mathrm{Cl} 0.17$ to $0.20)$. The $81+$ age group had the largest association with breaches (RR 7.77; 95\% Cl 5.32 to 11.34).

Conclusions Mandatory mask use was associated with a large increase in mask-wearing. Despite $14 \%$ of them wearing their masks incorrectly, mask users had a large reduction in the mean number of breaches (disease transmission opportunities). The elderly and transit users may warrant public health interventions aimed at improving mask use.

\section{STRENGTHS AND LIMITATIONS OF THIS STUDY}

$\Rightarrow$ This is a large study (over 36000 observations) of real-world use of masks by the public conducted in two North American cities.

$\Rightarrow$ By including an assessment of physical distancing breaches, we were able to demonstrate whether the observed mask-wearing errors actually led to increased opportunities for disease transmission.

$\Rightarrow$ Subject characteristics had to be estimated by data collectors and were unable to be confirmed.

$\Rightarrow$ Data were collected during the summer of 2020 and the results could differ depending on lockdown status.

\section{INTRODUCTION}

Public mask use was recommended in spring 2020 by national and international health authorities in order to slow the spread of COVID-19. ${ }^{2}$ Masks have subsequently become an integral part of everyday life in countries around the world. It is hoped that vaccination will reduce or remove the need for masking in public; however, population-wide vaccination against COVID-19 is limited by a number of factors. ${ }^{34}$ Following the discovery and approval of vaccines, there remain challenges in scaling manufacturing and delivery systems for global access, as well as vaccine hesitancy. Thus masks will continue to play an important role in COVID-19 disease control for an indeterminate time-period.

Laboratory studies demonstrate that face masks, when worn appropriately, reduce respiratory droplets and aerosols for coronavirus, influenza virus, and rhinovirus. ${ }^{5}$ The evidence that mask use by the public in community settings reduces COVID-19 transmission is limited. ${ }^{6-9}$ An epidemiological study found that states with mandatory masking policies via state executive orders had substantial declines in the daily COVID-19 
growth rate following implementation; however, actual compliance with the orders was not measured..$^{10}$ Maskwearing by the public was rated as poor in one study, ${ }^{11}$ but it was not conducted during a pandemic. Another study conducted in Hong Kong found that $>97 \%$ of the public were wearing masks during the 3-day study period in April 2020 ${ }^{12}$; however, it did not assess appropriate wear, and mask use in Hong Kong may not be representative of other regions. A trial in Denmark found no reduction in COVID-19 infections between subjects assigned to the recommendation to wear masks and those who were not, but only $46 \%$ of subjects in that trial setting reported wearing a mask as recommended. ${ }^{9}$ How frequently masks are worn in real life, in settings where they are recommended versus mandated, is not well established.

Incorrect mask use during a pandemic has the potential to increase rather than decrease disease transmission. ${ }^{13}$ In this study we examined how frequently members of the public wore a mask in multiple public venues (including during times of non-mandatory and mandatory mask use in indoor settings) in Toronto, Canada, and in Portland, Oregon, USA. We also assessed what proportion were worn incorrectly and the number of 'breaches' of physical distancing recommendations or episodes with potential for disease transmission (defined as coming within $2 \mathrm{~m}$ of another person ${ }^{14}{ }^{15}$ when both parties were not wearing a mask or wearing one but incorrectly). We hypothesised that masks would give the public a false sense of security, leading to reduced physical distancing, and along with a high rate of incorrect mask-wearing, this would result in more overall breaches among mask-wearers than among those who were not wearing a mask.

\section{METHODS}

\section{Study design}

This prospective observational study examined mask use by the public in multiple public locations between June and August 2020 in two urban cities: Toronto, Ontario, Canada, and Portland, Oregon, USA (see online supplemental appendix 1 for demographic information). A waiver of consent was obtained.

\section{Study population and setting}

All persons present at any of the study sites during a study shift were eligible; there were no exclusion criteria. Study sites were chosen a priori by the group via consensus, based on WHO guidelines on COVID-19 spread and mask use (ie, outdoors have a lower risk of spread) and anticipated differences in mask use by site. ${ }^{14} 15$ These included (in each city) six outdoor spaces (waterfront walkways, downtown streets, suburban business streets, public squares, parks, cemeteries), three retail stores (grocery store, drugstore/pharmacy (none in Portland), hardware store), airports (Pearson International Airport and Portland International Airport) and public transit (bus, subway, tram). Shifts were $\sim 4$ hours long and were performed during non-night-time hours (when there would be subjects present in stores, and enough elsewhere to be at risk of breaches), between 08:00 and 21:00. Each data collector was encouraged to divide their shifts evenly across those hours, and each attended at least two sites overall.

Data collection began in stores, airports, and outdoors in June, and a month later Toronto introduced a bylaw mandating mask-wearing on public transit (2 July 2020) ${ }^{16}$ and in all indoor public settings (7 July 2020), ${ }^{17}$ while the Pearson International Airport asked all airport patrons to mask on 1 June 2020 (ie, just prior to the start of data collection). ${ }^{18}$ Portland introduced mandates on 6 June 2020 , requiring that face masks be worn in any situation in which physical distancing could not be maintained. ${ }^{19}$ Therefore, all airport and all public transit study observations occurred in the setting of mandated mask use, while the majority (but not all) of observations made in stores did.

\section{Data collection and outcome measures}

A standardised data collection instrument was created in Excel (Microsoft, Redmond, Washington) by the first author and circulated among the study team. After several rounds of revisions, the Toronto team underwent a collective, standardised training process. The team met via recorded video conference to review $\sim 30$ min of video taken at several sites; this was conducted to minimise subjectivity that may exist in interpreting the selected metrics (eg, correct mask usage, adherence to physical distancing policies). Team members collectively reviewed each data point in the videos and discussed any discrepancies in interpretation or data collection as they occurred. In addition, the study team texted each other live from the sites during data collection in order to address any uncertainties that arose around definitions via consensus; this further ensured high interobserver reliability. As this was a purely observational study, without subject contact, the data collectors estimated each subject's age group $(0-10,11-30,31-65,66-80$, $81+)$ and sex. The recorded meeting was shared with the Portland team for their training session, along with the standardised data collection instrument; any discrepancies or questions were reviewed through collective discussion. Lastly, one member each of the Portland and Toronto teams viewed more (previously unseen) video footages taken in Toronto of 92 subjects to determine inter-rater reliability using Cohen's kappa: wearing a mask 0.96 and incorrect mask use 1.0.

Outcomes included mask use, mask error, and, because an error does not necessarily mean an opportunity for disease transmission, breaches. Based on the training videos, the team decided that certain sites might have such a high volume of passers-by that the data collector could not accurately record both mask use and breaches for every person present. In those high-volume situations, data collection of mask 
use and breaches was divided into two separate shifts, which were performed at the same time of day and day type (weekday or weekend). During the first shift, only mask use was assessed and, if worn, whether it was worn incorrectly and how. During the second shift at that same site, the data collector would follow one subject at a time, recording the number of breaches that occurred with other subjects, and not attempt to record every person present. The former shift would provide an overall rate of mask use and what proportion were incorrectly worn (and specific errors), and the latter would be used to determine breaches by mask group. This approach resulted in slightly different denominators for mask use and breaches.

For the purpose of our study, consistent with guidelines issued at the time of the study from both countries, ${ }^{12}$ a mask was defined as either a surgical mask, N95 respirator, cloth mask, a gaiter, and a cover over a baby stroller. A face shield worn without a mask was considered 'no mask'. Incorrect mask use involved a mask with exposure of either the nares, the mouth or both. Four specific types of incorrect mask use were defined a priori; all others were documented as 'other'. The definition of a breach had to have the potential for spread of COVID-19 and was based on the Public Health Agency of Canada and the Centers for Disease Control and Prevention guidelines: coming within $2 \mathrm{~m}$ or 6 feet of another person, ${ }^{14} 15$ when both parties either had no mask or a mask that was worn incorrectly (ie, if two or more subjects came within $2 \mathrm{~m}$ but one or both parties were wearing a mask correctly, it was not considered a breach).

\section{Data analysis}

We used descriptive statistics to describe subject characteristics, as appropriate. To assess the variables that were independently associated with wearing a mask, we fitted a logistic regression model that included the following variables: age group, sex, accompanied (ie, not alone), city, mandatory mask-use setting, and setting type. We used the same variables in logistic regression modelling to estimate the odds of making a mask error, restricting that analysis to subjects who were wearing a mask. Lastly, to answer our study hypothesis, we fitted a negative binomial regression model regressing the number of breaches on the same variables. The independent variable of interest was wearing a mask.

In all regression models, we decided a priori to test for an interaction between age group and whether the person was accompanied, hypothesising that young people in groups would be less likely to wear masks and more likely to make mask errors and breaches than older persons accompanied by another person or in a group. For all analyses, a p value of 0.05 or less was considered significant. Analyses were performed with Excel and SAS V.9.3.

\section{Patient and public involvement}

The rapid timeframes in which the research was conducted limited the scope for public involvement in study design or execution. Permission and input were obtained from privately owned indoor settings.

\section{RESULTS}

After removal of $26(0.07 \%)$ subjects who did not have their mask use recorded, 36808 individual observations remained in this cross-sectional study. There were slightly more observations made in Toronto $(56.3 \%)$ than in Portland $(43.7 \%)$. The largest estimated age group was 'adult' or age 31-65 years $(48.6 \%)$, followed by $11-30$ years $(39.0 \%)$ (table 1$)$. The slight majority were estimated to be male $(53.9 \%)$ and $43.9 \%$ were accompanied by someone.

Two-thirds $(67.7 \%$; 95\% CI 67.2 to 68.1$)$ of the subjects were wearing a mask. Mask use ranged by setting type, from $41.9 \%$ in outdoor spaces to $97.2 \%$ in stores. Among only settings with mandatory mask use, mask use ranged from $79.2 \%$ on public transit to $98.2 \%$ in stores. After adjustment, mandatory mask use was overwhelmingly associated with wearing a mask (OR 79.2; 95\% CI 47.4 to 135.1) (figure 1). As the estimated age increased, the adjusted odds of wearing a mask did as well. Females were more likely to wear masks than males (OR 1.39; 95\% CI 1.31 to $1.47)$, as were subjects in Portland compared with Toronto (OR 5.98; 95\% CI 5.61 to 6.38). Compared with inside stores, subjects at the airport (OR 0.36; $95 \%$ CI 0.28 to 0.46 ) and on public transit (OR 0.09 ; $95 \%$ CI 0.07 to 0.11 ) were less likely to wear a mask, as were subjects who were accompanied by someone else (OR 0.73 ; $95 \%$ CI 0.70 to 0.78 ). The interaction variable for age group and being accompanied was not significant $(\mathrm{p}=0.07)$.

Of the 24909 subjects wearing a mask, 3365 (13.5\%; 95\% CI 13.1 to 13.9 ) wore their mask incorrectly (table 1 ). The percentage of subjects wearing a mask incorrectly varied across setting type, from $7.9 \%$ in mandatory mask-use stores to $20.0 \%$ outdoors (figure 2 ). In mandatory mask-use settings, the proportion of people wearing it incorrectly ranged from $7.9 \%$ in stores to $17.0 \%$ on public transit. In the adjusted analyses, the variable with the largest effect size on wearing a mask incorrectly was mandatory mask use (OR 0.30; 95\% CI 0.14 to 0.73 ) (figure 3). Compared with the adult age group, only the 11-30years and eldest (81+ years) groups were associated with making a mask error (less likely and more likely, respectively). Females were less likely than males to make a mask-wearing error (OR 0.78 ; $95 \% \mathrm{CI} 0.72$ to 0.84 ), as were Portland subjects compared with those in Toronto (OR 0.46; $95 \%$ CI 0.42 to 0.50 ). Airport (OR 1.70; 95\% CI 1.50 to 1.95 ) and transit (OR 2.36; 95\% CI 2.03 to 2.74) settings were both associated with more mask-wearing errors compared with in stores. The interaction between age and being accompanied was not significant $(\mathrm{p}=0.07)$. 
Table 1 Study cohort, overall and by study setting type

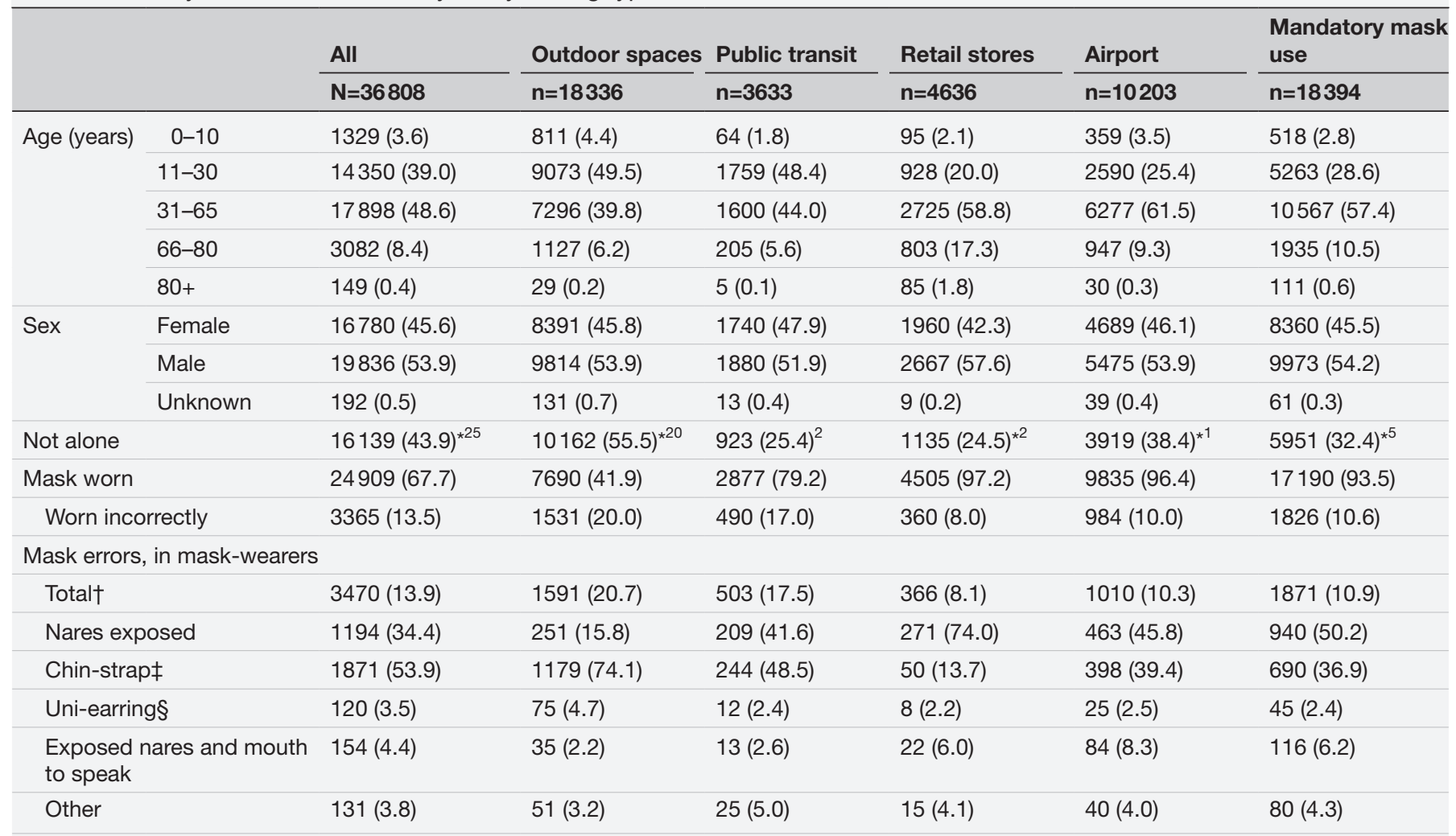

*Number of missing data points.

$\dagger$ Each subject can make more than one error.

$\ddagger$ Nares and mouth exposed.

§Hanging from one ear.

Among subjects observed to make a mask-wearing error, the most common documented error was the 'chin-strap', where both the nares and the mouth were exposed (53.9\%) (table 1). The next most frequent error was exposure of the nares $(34.4 \%)$, followed by pulling the mask down to speak (4.4\%). By setting, the 'chin-strap' error constituted the large majority of incorrect wear in outdoor spaces $(74.1 \%$; $95 \%$ CI 71.9 to 76.2 ) and the slight majority on public transit (48.5\%; $95 \%$ CI 44.1 to 53.0) (figure 2). Wearing the mask with solely

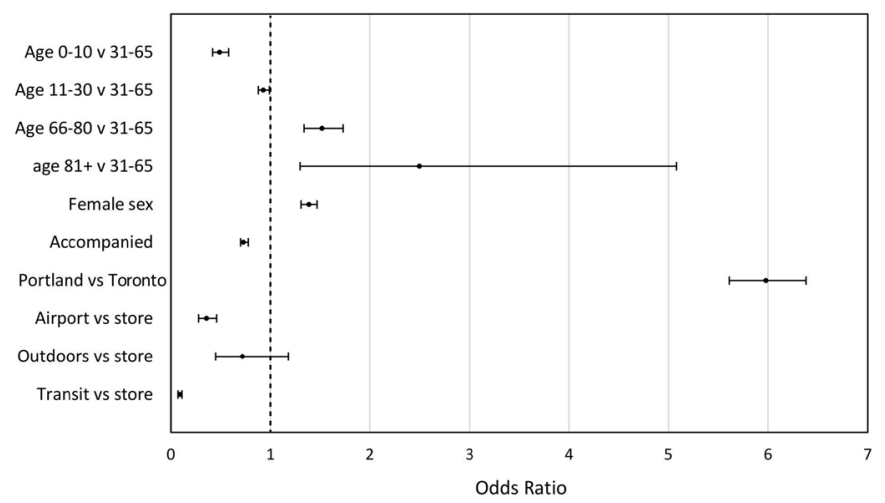

Figure 1 Adjusted odds of wearing a mask. Mandatory mask use setting OR was not plotted to improve graph readability: OR $79.2 ; 95 \% \mathrm{Cl} 47.4$ to 135 . The interaction between age group and being accompanied was not significant $(p=0.07)$. the nares exposed was the predominant mask error made in stores $(74.0 \%)$ and airports (45.8\%). Combining all settings with mandatory mask use, the predominant mask-wearing error was having solely the nares exposed $(50.2 \%$; $95 \%$ CI 47.9 to 52.5$)$.

Overall, 9021 breaches were observed, for a rate of 26 breaches per 100 persons observed (figure 4 ). The number of breaches was much higher in the non-mask-wearing group (66 of 100 persons observed) compared with the group wearing a mask (including those wearing it correctly and not) (7 of 100 persons observed). This relationship was maintained across all settings. Specifically, while the rate of breaches was very high in the group who wore a mask but wore it incorrectly (55 of 100 persons observed), once included with the other mask-wearing subjects (ie, those who wore it correctly) the overall number of breaches among the maskwearing group was far below that of the non-mask-wearing group. The adjusted rate ratio (RR) of a breach if wearing a mask compared with not wearing one was 0.19 (95\% CI 0.17 to 0.20 ) (figure 5 ). Other variables independently associated with the number of breaches, in order of declining effect size, included being in the elderly ( $>80$ years) age group (RR 7.77; 95\% CI 5.32 to 11.34) versus the adult group, being on transit (RR 3.22; 95\% CI 2.68 to 3.88) versus in a store, mandatory mask use (RR $0.50 ; 95 \%$ CI 0.28 to 0.87 ), age $66-80$ years (RR $1.32 ; 95 \%$ CI 1.16 to 1.50 ) versus 

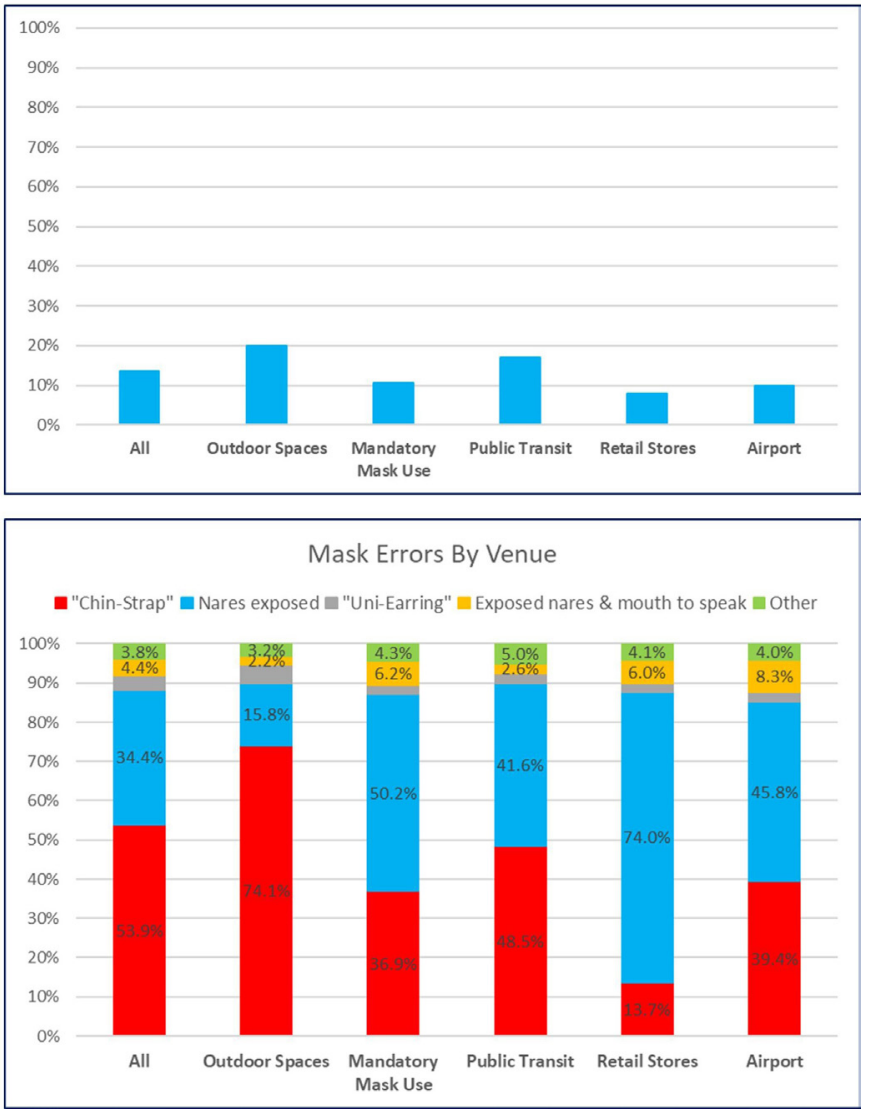

Figure 2 Masked subjects who exhibited incorrect maskwearing practices by setting (top) and types of errors by setting (bottom).

adult, and being with someone else (RR 1.18; 95\% CI 1.10 to 1.26 ). Portland subjects (RR 0.93 ; $95 \%$ CI 0.87 to 1.00 ) versus Toronto subjects had a borderline association. The interaction term in the breaches model was not significant $(\mathrm{p}=0.0523)$. Thus, in contrast to our a priori hypothesis that younger persons who were with someone would be more likely to have breaches than older accompanied persons, the younger adult group was not associated with an increased number of breaches.

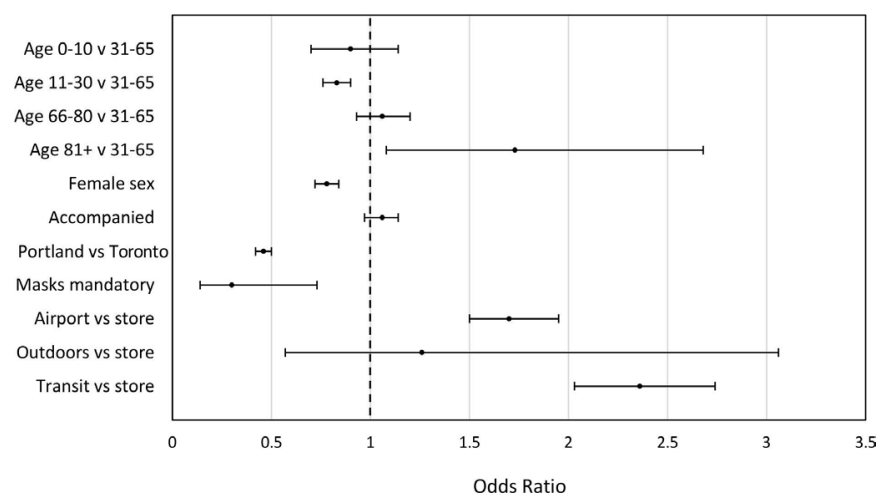

Figure 3 Adjusted odds of wearing a mask incorrectly among subjects wearing a mask. The interaction term for age group and being accompanied was not significant $(p=0.07)$.
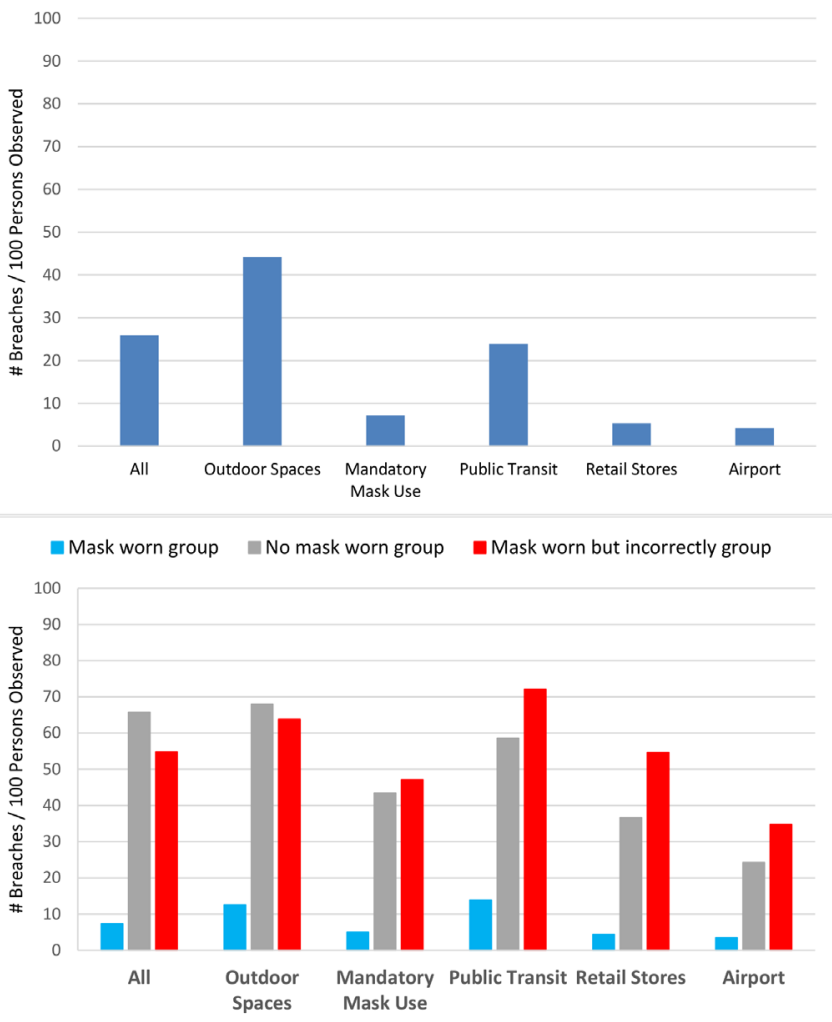

Figure 4 Breaches by venue type (top) and by masking (bottom). Note that the group with mask worn but worn incorrectly is a subset of the group with mask worn.

\section{DISCUSSION}

With the majority of the world's inhabitants under advisement to wear masks in public places to prevent the spread of COVID-19, it is imperative to know how often this advice is being followed, how well it is being executed, and the resulting number of opportunities for disease transmission. In this study of over 35000 observations in two urban North American cities, we found that two-thirds of inhabitants wore a mask in public. This is similar to a study in Chittenden

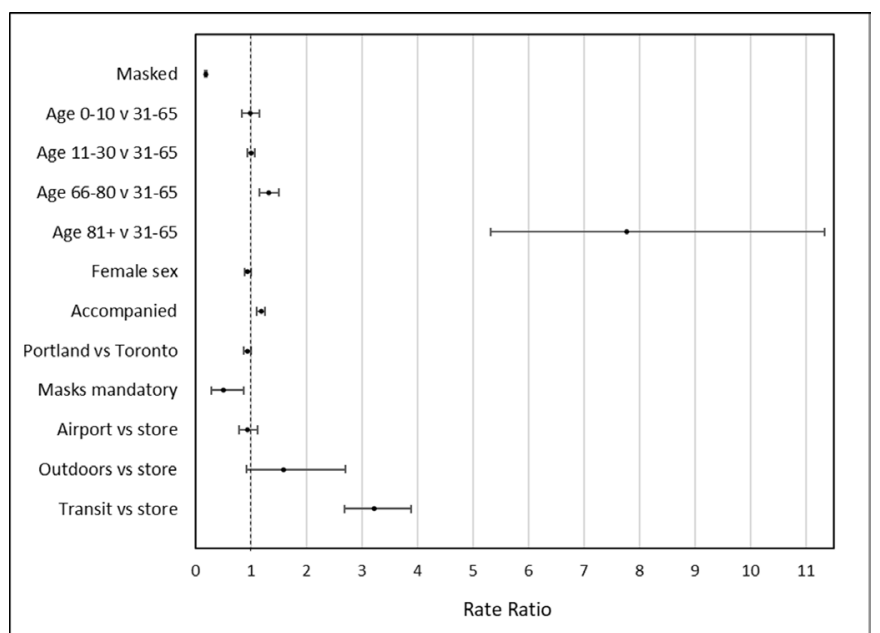

Figure 5 Adjusted rate ratios for breaches. The interaction term for age group and being accompanied was not significant $(p=0.0523)$. 
County, Vermont, which found that $75.5 \%$ of the 1004 persons observed following the lifting of lockdown in May 2020 wore a mask. ${ }^{20}$ Consistent with that study, we found that females and older persons had higher adjusted odds of masking. Another US study found that the daily COVID-19 growth rate fell following the institution of state-wide mandates to wear masks, ${ }^{10}$ and our study demonstrates that mandating mask use in public spaces is strongly associated with compliant mask-wearing by the public. Taken together, it suggests that mask-use mandates are effective at improving mask-wearing and limiting COVID-19 spread.

Appropriately, we found that the proportion of maskwearing was lower in outdoor spaces $(42 \%)$, consistent with guidelines and lower risk of transmission, ${ }^{21}{ }^{22}$ and very high $(>95 \%)$ in indoor public spaces with mandatory maskwearing rules, such as stores and airports. Less appropriately, the proportion wearing a mask on public transit (which was mandatory for the duration of the study) fell between the two, at $79 \%$. Unfortunately, $18 \%$ of the latter group were also wearing their mask incorrectly, as were $20 \%$ of the subjects who wore a mask outdoors and $11 \%$ of those in mandatory mask-use settings. These findings suggest that initiatives on how to wear a mask properly and reminders in certain public spaces may be needed.

It is possible that 'judicious' incorrect mask-wearing, or wearing a mask incorrectly when farther than $2 \mathrm{~m}$ from anyone else but positioning it properly if coming within $2 \mathrm{~m}$ of another person, may be occurring. We hypothesised that incorrect mask use with the 'chin-strap', which was most popular in spacious outdoor settings, might be a purposeful choice. In comparison, we hypothesised that the nares exposed might be an inadvertent error (perhaps the top band was not 'pinched' properly, or the mask was too big or worn upside down, or the straps were too long). However, many of the subjects observed to be wearing their mask as a 'chin-strap' subsequently had a breach (among outdoor subjects, 63 breaches per 100 persons observed). These findings suggest that if done purposefully, 'judicious' maskwearing does not work particularly well.

Despite the high number of breaches among people who wore their mask incorrectly, the high proportion of maskwearers who wore their mask correctly (and were subsequently unable to breach) diluted the overall number of breaches to a much lower level in the mask-wearing group relative to the non-mask-wearing group. This is contrary to our a priori hypothesis, with similar results after adjustment for potential confounders. Of note, in addition to much higher adjusted odds of making a mask-wearing error, the elderly also had a very high adjusted rate of breaches relative to younger persons, which could be secondary to a false sense of security when wearing a mask. The high rate of breaches is particularly worrisome given that they are the age group at the highest risk. ${ }^{23}{ }^{24}$ This suggests that future interventions that target this group are urgently needed.

Limitations of our study include the setting of two urban North American cities where the study teams were based; our results may not apply to non-North American countries with differing governmental responses to COVID-19 and infection levels. Given enormous social inequalities both within and between countries, where vulnerable/marginalised people live in environments that favour agglomerations, our results may not apply to low-income and middle-income countries. In order to include a large and representative sample of the public, as well as avoid the bias introduced by the consent process, we did not consent subjects, and in turn we had to estimate their characteristics rather than collect this information. Despite our large numbers, the sample size of the elderly age group was small, likely due to the advisory for this group to stay at home.

Certain mask-wearing errors were momentary, and if there was uncertainty we gave subjects the benefit of the doubt and did not count it as an error; for example, a subject who boarded a bus without a mask but immediately took a mask from the provided dispenser (and put it on correctly) was not counted as an error. Similarly, we did not count pulling the mask down to eat as a mask error given that human beings need to eat and cannot do so wearing a mask correctly. This may have resulted in a slightly conservative estimate of mask-wearing errors. It is possible that the same subject was observed twice, if they returned to the same location during a shift, or even another location that was a study site. Data collectors were encouraged to divide their time equally between morning, afternoon, and evening blocks, but this was not mandatory, making this a convenience sample. Because the study was purely observational, variables that were included in our models were limited to observable characteristics: unmeasured variables could affect the outcome. There were $\sim 3465$ new COVID-19 cases in Toronto during our study period (population 2700 000) and 4795 in Multnomah County, Portland (population $\sim 650000$ ), raising the possibility that mask-wearing was higher in the latter city due to a higher infection rate; however, we did not formally explore reasons behind the adjusted differences in mask-wearing between the two cities. This would make an excellent future study. Lastly, public compliance with mask-wearing likely varies over time, in relation to the number of COVID-19 cases. If cases drop to near zero, our results may not apply.

\section{CONCLUSIONS}

Compliance with recommendations to wear a mask was relatively high in two North American cities in the summer months of 2020. It was far from perfect, however, particularly on public transit. Elderly persons were the most likely to make mask-wearing errors and therefore should be targeted by educational mask-wearing campaigns. A mandatory requirement to wear a mask was the greatest predictor of both mask-wearing and correct wear and was not associated with an inadvertent increase in breaches. These results support mandating mask use in public settings as an effective public health strategy to prevent the spread of COVID-19.

Author affiliations

${ }^{1}$ Sunnybrook Health Sciences Centre, Toronto, Ontario, Canada

${ }^{2}$ ICES, Toronto, Ontario, Canada 
${ }^{3}$ Institute of Health Policy, Management and Evaluation, University of Toronto, Toronto, Ontario, Canada

${ }^{4}$ Oregon Health \& Science University, School of Medicine, Portland, Oregon, USA ${ }^{5}$ Division of Vascular Surgery, Department of Surgery, University of Toronto, Toronto, Ontario, Canada

${ }^{6}$ Temerty Faculty of Medicine, University of Toronto, Toronto, Ontario, Canada ${ }^{7}$ University of Ottawa Faculty of Medicine, Ottawa, Ontario, Canada

${ }^{8}$ Center for Policy and Research in Emergency Medicine, Department of Emergency Medicine, Oregon Health \& Science University, Portland, Oregon, USA

Twitter Clare L Atzema @Atzema, Peter C Austin @stats_research, Arshia P Javidan @APJavidan and Allen Li @allenlimed

Contributors Study concept and design: CLA, IM, PCA, APJ, LW, AL, RVP, DDL, NPL, EAL, DB, BK. Acquisition of data: IM, APJ, LW, AL, RVP, DDL, NPL, EAL, DB, HN, CC, AC, BC, SB, TF, TZ, RDS, PCMB. Analysis and interpretation of data: all. Drafting of the manuscript: CLA. Critical revision of the manuscript for important intellectual content: all. Statistical analysis: CLA, IM, PCA, DB, BK. CLA is responsible for the overall content as the guarantor.

Funding Individual authors received salary support. CLA was supported by a Mid-Career Investigator Award from the Heart and Stroke Foundation of Ontario (HSF0), the Practice Plan of the Department of Emergency Services at Sunnybrook Health Sciences, Sunnybrook Research Institute, and ICES. PCA was supported by a Mid-Career Investigator Award from HSF0. BK was supported by an NIH NHLBI K08 grant (\#HL140105). This study was supported by ICES, which is funded by an annual grant from the Ontario Ministry of Health and Long-Term Care (MOHLTC).

Disclaimer The Heart and Stroke Foundation of Ontario had no involvement in the design or conduct of the study, data management or analysis, or manuscript preparation, review or authorisation for submission. The opinions, results and conclusions reported in this paper are those of the authors and are independent of the funding sources. No endorsement by ICES or the Ontario MOHLTC is intended or should be inferred.

Competing interests None declared.

Patient consent for publication Not required.

Ethics approval Ethics approval for the study was obtained from the Research Ethics Board of Sunnybrook Health Sciences Centre (project ID: 2019 06/15/2020). The Oregon Health \& Science University Internal Review Board considered this a non-human subjects study and waived consent.

Provenance and peer review Not commissioned; externally peer reviewed.

Data availability statement Data are available upon reasonable request. Deidentified data is available from the authors upon request.

Supplemental material This content has been supplied by the author(s). It has not been vetted by BMJ Publishing Group Limited (BMJ) and may not have been peer-reviewed. Any opinions or recommendations discussed are solely those of the author(s) and are not endorsed by BMJ. BMJ disclaims all liability and responsibility arising from any reliance placed on the content. Where the content includes any translated material, BMJ does not warrant the accuracy and reliability of the translations (including but not limited to local regulations, clinical guidelines, terminology, drug names and drug dosages), and is not responsible for any error and/or omissions arising from translation and adaptation or otherwise.

Open access This is an open access article distributed in accordance with the Creative Commons Attribution Non Commercial (CC BY-NC 4.0) license, which permits others to distribute, remix, adapt, build upon this work non-commercially, and license their derivative works on different terms, provided the original work is properly cited, appropriate credit is given, any changes made indicated, and the use is non-commercial. See: http://creativecommons.org/licenses/by-nc/4.0/.

\section{ORCID iDs}

Clare L Atzema http://orcid.org/0000-0002-7236-5522

Ivona Mostarac http://orcid.org/0000-0001-9621-983X

Arshia P Javidan http://orcid.org/0000-0002-7541-2857

Allen Li http://orcid.org/0000-0001-6615-7295

Trevor Funari http://orcid.org/0000-0002-1465-2590

\section{REFERENCES}

1 Centers for Disease Control and Prevention. Considerations for wearing masks, 2020. Available: https://www.cdc.gov/coronavirus/ 2019-ncov/prevent-getting-sick/cloth-face-cover.html [Accessed 24 Nov 2020].

2 Harris K. Canadians should wear masks as an 'added layer of protection,' says Tam. CBC News, 2020. Available: https://www. cbc.ca/news/politics/masks-covid-19-pandemic-public-health-1. 5576895 [Accessed 28 Jul 2021].

3 Corey L, Mascola JR, Fauci AS, et al. A strategic approach to COVID-19 vaccine R\&D. Science 2020;368:948-50.

4 World Health Organization. Guidance on developing a national deployment and vaccination plan for COVID-19 vaccines, 2020 Available: https://www.who.int/publications/i/item/WHO-2019-nCoVVaccine deployment-2020.1 [Accessed 24 Nov 2020].

5 Leung NHL, Chu DKW, Shiu EYC, et al. Respiratory virus shedding in exhaled breath and efficacy of face masks. Nat Med 2020;26:676-80.

6 Chou R, Dana T, Jungbauer R, et al. Update alert 3: masks for prevention of respiratory virus infections, including SARS-CoV-2, in health care and community settings. Ann Intern Med 2020;173:169.

7 Chou R, Dana T, Jungbauer R, et al. Masks for Prevention of Respiratory Virus Infections, Including SARS-CoV-2, in Health Care and Community Settings : A Living Rapid Review. Ann Intern Med 2020;173:542-55.

8 Doung-Ngern P, Suphanchaimat R, Panjangampatthana A, et al. Case-Control study of use of personal protective measures and risk for SARS-CoV 2 infection, Thailand. Emerg Infect Dis 2020;26:2607-16.

9 Bundgaard H, Bundgaard JS, Raaschou-Pedersen DET, et al. Effectiveness of Adding a Mask Recommendation to Other Public Health Measures to Prevent SARS-CoV-2 Infection in Danish Mask Wearers : A Randomized Controlled Trial. Ann Intern Med 2021;174:335-43.

10 Lyu W, Wehby GL. Community use of face masks and COVID-19: evidence from a natural experiment of state mandates in the US. Health Aff 2020;39:1419-25.

11 Lee LY-K, Lam EP-W, Chan C-K, et al. Practice and technique of using face mask amongst adults in the community: a cross-sectional descriptive study. BMC Public Health 2020;20:948.

12 Cheng VC-C, Wong S-C, Chuang VW-M, et al. The role of community-wide wearing of face mask for control of coronavirus disease 2019 (COVID-19) epidemic due to SARS-CoV-2. J Infect 2020;81:107-14.

13 World Health Organization. Advice on the use of masks in the community setting in Influenza A (H1N1) outbreaks 2009.

14 Centers for Disease Control and Prevention. Social distancing, 2020. Available: https://www.cdc.gov/coronavirus/2019-ncov/ prevent-getting-sick/social-distancing.html [Accessed 23 Nov 2020].

15 Public Health Agency of Canada. Physical distancing: how to slow the spread of COVD-19, 2020. Available: https://www.canada.ca/ content/dam/phac-aspc/documents/services/publications/diseasesconditions/coronavirus/social-distancing/physical-distancing-eng.pdf [Accessed 3 Oct 2020].

16 Toronto Transit Commission. Face masks and face coverings, 2020. Available: http://www.ttc.ca/COVID-19/Masks/index.jsp [Accessed 20 Oct 2021]

17 City of Toronto. COVID-19: mandatory mask or face covering bylaws, 2020. Available: https://www.toronto.ca/home/covid-19/covid-19what-you-should-do/covid-19-orders-directives-by-laws/mandatorymask-or-face-covering-bylaw/ [Accessed 3 Oct 2020].

18 Declerq K. Masks now mandatory for all staff and travelers at Pearson. CTV news web site, 2020. Available: https://toronto. ctvnews.ca/masks-now-mandatory-for-all-staff-and-travellers-atpearson-1.4963473?cache=\%3Fclipld\%3D104056\%3FautoPlay\% 3Dtrue

19 Governor Kate Brown. Executive order 20-27, 2020. Available: https://www.oregon.gov/gov/admin/Pages/eo_20-27.aspx [Accessed 24 Nov 2020].

20 Beckage B, Buckley T, Beckage M. Prevalence of mask wearing in northern Vermont in response to SARS-CoV-2. MedRxiv 2020.

21 Centers for Disease Control and Prevention. Deciding to go out, 2020. Available: https://www.cdc.gov/coronavirus/2019-ncov/dailylife-coping/deciding-to-go-out.html [Accessed 24 Nov 2020].

22 Government of Canada. COVID-19: main modes of transmission, 2020. Available: https://www.canada.ca/en/public-health/services/ diseases/2019-novel-coronavirus-infection/health-professionals/ main-modes-transmission.html [Accessed 24 Nov 2020].

23 Grasselli G, Zangrillo A, Zanella A, et al. Baseline characteristics and outcomes of 1591 patients infected with SARS-CoV-2 admitted to ICUs of the Lombardy region, Italy. JAMA 2020;323:1574-81.

24 Zhou F, Yu T, Du R, et al. Clinical course and risk factors for mortality of adult inpatients with COVID-19 in Wuhan, China: a retrospective cohort study. Lancet 2020;395:1054-62. 